\title{
Sildenafil for adult Asian patients with pulmonary arterial hypertension: a systematic review and meta-analysis
}

\author{
Qianling Shi ${ }^{1,2}$, Zijun Wang ${ }^{1}$, Nan Yang ${ }^{1}$, Yanfang $\mathrm{Ma}^{3}$, Yaolong Chen ${ }^{1,2,4,5}$, Hulai Wei ${ }^{6}$, Hua Yao ${ }^{7}$ \\ ${ }^{1}$ Evidence-based Medicine Center, School of Basic Medical Sciences, Lanzhou University, Lanzhou, China; ${ }^{2}$ Lanzhou University Institute of Health \\ Data Science, Lanzhou, China; ${ }^{3}$ School of Chinese Medicine, Hong Kong Baptist University, Hong Kong, China; ${ }^{4}$ WHO Collaborating Center \\ for Guideline Implementation and Knowledge Translation, Lanzhou, China; ${ }^{5}$ Lanzhou University GRADE Center, Lanzhou, China; ${ }^{6}$ Key Lab \\ of Preclinical Study for New Drugs of Gansu Province, School of Basic Medical Sciences, Lanzhou University, Lanzhou, China; ${ }^{7}$ Department of \\ Cardiology, Guangdong Provincial People's Hospital, Guangzhou, China \\ Contributions: (I) Conception and design: H Yao; (II) Administrative support: H Yao, H Wei; (III) Provision of study materials or patients: Q Shi; (IV) \\ Collection and assembly of data: Q Shi, Z Wang, N Yang, Y Ma, Y Chen; (V) Data analysis and interpretation: Q Shi; (VI) Manuscript writing: All \\ authors; (VII) Final approval of manuscript: All authors. \\ Correspondence to: Hulai Wei. Key Lab of Preclinical Study for New Drugs of Gansu Province, School of Basic Medical Sciences, Lanzhou University, \\ Lanzhou, China. Email: weihulai@lzu.edu.cn; Hua Yao. Department of Cardiology, Guangdong Provincial People’s Hospital, Guangzhou, China. \\ Email: yaohua2078@163.com.
}

Background: The prognosis of patients with untreated pulmonary arterial hypertension (PAH) has historically been poor. Previous studies have recommended that sildenafil was beneficial, but the dose varies greatly. In this study, we aimed to evaluate the safety and effectiveness of sildenafil [dose: $20 \mathrm{mg} /$ three times a day (TID)] for adult Asian PAH patients.

Methods: Electronic databases (MEDLINE, Embase, Web of Science, the Cochrane Library, CBM, CNKI, and Wanfang Data) were searched from their inception to January 2022. We recruited all randomized controlled trials and non-randomized studies of interventions that compared sildenafil (20 mg/TID) versus placebo or symptomatic treatment for adult Asian PAH patients.

Results: A total of 10 studies involving 480 participants were included. Compared to symptomatic treatment, sildenafil-treated patients were more likely to walk 57.68 meters further in six-minute walk distance [mean difference $(\mathrm{MD})=57.68 \mathrm{~m}, 95 \%$ confidence interval (CI): 41.55 to 73.81 ], achieve an improvement in systemic arterial oxygen saturation ( $\mathrm{MD}=2.48 \%, 95 \% \mathrm{CI}: 1.26$ to 3.71 ), and increase the score of the Borg scale for dyspnea (MD $=-0.99$ points, $95 \% \mathrm{CI}$ : -1.45 to -0.53 ). The total number of patients with World Health Organization class III and IV also exhibited a downtrend. Compared to the placebo, sildenafil was associated with a reduction in the mean pulmonary artery pressure ( $\mathrm{MD}=-4.13 \mathrm{mmHg}, 95 \% \mathrm{CI}:-6.52$ to $-1.74)$ and the level of brain natriuretic peptide ( $\mathrm{MD}=-86.16 \mathrm{pg} / \mathrm{mL}, 95 \% \mathrm{CI}:-103.39$ to -68.93$)$. The most common adverse events were headache, flushing, dyspepsia, and diarrhea, which were relatively mild.

Discussion: Sildenafil at a dose of $20 \mathrm{mg} / \mathrm{TID}$ is well tolerated in adult Asian PAH patients, and is associated with statistically significant improvements in exercise capacity, cardio-pulmonary function, and haemodynamic indices. The long-term prognosis still needs to be evaluated and confirmed by further trials.

Koywords: Sildenafil; pulmonary arterial hypertension (PAH); systematic review; meta-analysis

Submitted Dec 14, 2021. Accepted for publication Jan 19, 2022.

doi: 10.21037/apm-21-3979

View this article at: https://dx.doi.org/10.21037/apm-21-3979 


\section{Introduction}

Pulmonary hypertension (PH) is a group of complex conditions characterized by a progressive increase in pulmonary artery pressure (PAP) with or without irreversible vascular remodeling, leading to right ventricular failure and premature death. Present estimates suggest a $\mathrm{PH}$ prevalence of about $1 \%$ of the global population, which increases to up to $5-10 \%$ in individuals aged $>65$ years $(1,2)$. Based on the clinical presentations, pathophysiological and haemodynamic characteristics, $\mathrm{PH}$ can be classified into five groups, among which, the pulmonary arterial hypertension (PAH) refers to a group of diseases where $\mathrm{PH}$ occurs in the setting of increased pulmonary vascular resistance (PVR) (3-5). The overall estimated rate of PAH is $10-52$ per million of the population (6), and the reported incidence and prevalence in the developed world is 1.1-7.6 and 6.6-26.0 per million adults per year, respectively (7-9). For patients without effective treatment, PAH can be hugely devastating and exert an adverse impact on all aspects of life. The prognosis was once very poor, with a median survival of only 2.8 years $(10,11)$. Recent years have seen the introduction of targeted medications to enhance the survival rate of patients, with an improvement in the 1-year survival rate from $69 \%$ to $85 \%$ and the 5 -year survival rate from $38 \%$ to $57 \%$ (12-14).

Sildenafil was first approved for the management of PAH in 2005 by both the Food and Drug Administration (FDA) and the European Medicines Agency (EMA) for oral administration at a dose of $20 \mathrm{mg} /$ three times a day (TID). It specifically reduces the activity of the cyclic guanosine monophosphate (cGMP) degrading enzyme, thereby increasing the antiproliferative and vasodilatory effects of endogenous nitric oxide (NO) $(4,15)$. Due to its reliable efficacy, good tolerability, and affordability (the average cost in the United States for 1 year of treatment with sildenafil $20 \mathrm{mg} / \mathrm{TID}$ (13,000 dollars), which compares favorably with bosentan (annual cost, 40,000 dollars), sildenafil has become the drug of choice for PAH patients with World Health Organization (WHO) II or III functional class, and has been recommended in several guidelines (4,16-19). Although a number of systematic reviews have confirmed its shortterm clinical efficacy $(16,20,21)$, the dose varies greatly, and the previous studies did not focus on Asian population and other important outcomes. Specifically for China, iloprost and bosentan were approved for the treatment of $\mathrm{PAH}$, but few patients have been treated with these agents, because the cost of a 1-month supply of bosentan and iloprost ( 3,000 dollars) is significantly higher than sildenafil $20 \mathrm{mg}$ /TID (300 dollars) per month (22). Therefore, the purpose of this study is to quantify the safety and effectiveness of sildenafil $(20 \mathrm{mg} / \mathrm{TID})$ for adult PAH patients in Asia, in order to provide guidance for patient preferences, clinician treatment choices, and guideline development.

We present the following article in accordance with the Preferred Reporting Items for Systematic Review and MetaAnalysis (PRISMA) reporting checklist (23) (available at https://apm.amegroups.com/article/view/10.21037/apm-213979/rc) and PRISMA extension for literature searches (24).

\section{Methods}

Our protocol was registered in PROSPERO (registration number CRD42020190582).

\section{Search strategy}

Two researchers (Shi and Wang) independently searched the following databases up to 7 January 2022: MEDLINE (via PubMed), Embase, Web of Science, The Cochrane Library, China Biology Medicine (CBM), China National Knowledge Infrastructure (CNKI) and Wanfang Data (25). We also searched clinical trial registry platforms (US National Institutes of Health Trials Register and WHO Clinical Trials Registry Platform), Google Scholar, as well as the reference lists of the retrieved articles to identify studies that may have been missed.

The search strategy was also peer reviewed by an external specialist. We systematically searched by combining the medical subject headings (MeSH) and free words. The keywords and terms in the MEDLINE database included "sildenafil", "Pulmonary Arterial Hypertension", "PAH" and their derivatives. The detailed search strategies can be found in the Appendix 1.

\section{Inclusion and exclusion criteria}

\section{Types of studies}

We included all randomized controlled trials (RCTs) and non-randomized studies of interventions (NRSIs) that compared effectiveness and safety of sildenafil (20 mg/TID) with a placebo, as well as those that compared the combination of sildenafil (20 mg/TID) and symptomatic treatment with symptomatic treatment alone. Considering that PAH is a rare disease and there may be a lack of studies, we also included multi-center RCTs and NRSIs 
involving adult Asian PAH patients. In vitro studies, animal experiments, and basic researches were excluded. Duplicates, articles written in languages other than English or Chinese, and conference abstracts were also excluded.

\section{Types of participants}

We included any adult Asian patient with a diagnosis of $\mathrm{PAH}$ who required medical treatment for their condition. We defined $\mathrm{PAH}$ as a mean $\mathrm{PAP} \geq 25 \mathrm{mmHg}$ by right-heart catheterisation according to accepted criteria $(3,17,18)$, and included the following categories: (I) idiopathic PAH; (II) $\mathrm{PAH}$ with vasoreactivity; (III) heritable PAH; (IV) drug and toxin-related PAH; (V) PAH associated with connective tissue disease (CTD), human immunodeficiency virus (HIV), portal hypertension, congenital heart disease (CHD), and schistosomiasis; and (VI) pulmonary veno-occlusive disease or pulmonary capillary haemangiomatosis.

\section{Types of outcome measures}

The primary outcomes were 6-minute walk distance (6MWD), dyspnoea score on any scale, level of brain natriuretic peptide (BNP), change in $\mathrm{WHO}$ functional class, mean PAP, systemic arterial oxygen saturation, and adverse events. The secondary outcomes included but were not limited to haemodynamic parameters [right atrium pressure (RAP), PVR, cardiac index], quality of life, time to clinical worsening, as well as the incidence of clinical worsening and mortality.

\section{Study selection}

After eliminating duplicates, two researchers (Shi and Wang) independently screened the titles, abstracts, and full-texts of potentially relevant articles using pre-defined criteria. Discrepancies were discussed or resolved with a third researcher (Yang). All reasons for excluding ineligible studies were recorded. The process of study selection was documented using a PRISMA flow diagram (23).

\section{Data extraction}

Two researchers (Shi and Wang) independently extracted data using a pre-determined data collection form. Disagreements were resolved by discussion. We extracted the following data: (I) methods: first author, study design, study setting, number of study centers and location; (II) participants: sample, age, gender, diagnostic criteria, important baseline data, inclusion and exclusion criteria;
(III) intervention: dose, mode of administration, and control measures; (IV) outcomes: primary and secondary outcomes as specified, type of scale used, time points collected (for dichotomous data, the number of events, and total participants in per group; for continuous data, means, standard deviations (SD), and the number of total participants in per group); (V) trial design characteristics as outlined in the "risk of bias assessment in included studies" section; and (VI) other: funding and conflicts of interest for trial authors.

\section{Risk of bias assessment}

Four researchers (Shi, Wang, Yang and $\mathrm{Ma}$ ) assessed the risk of bias for included studies independently in pairs. Discrepancies were resolved by discussion. For RCTs, we used the Cochrane Risk-of-Bias assessment tool (26), and graded each bias as low risk, unclear risk (insufficient information to form a judgment), or high risk. For NRSIs, we used the Risk-of-Bias In non-randomized Studies-of Interventions (ROBINS-I) tool (27), and graded each bias as low, moderate, serious, critical, and no information.

\section{Statistical analysis}

We performed meta-analysis of outcomes for which the data were sufficiently compatible. For dichotomous data, we calculated the odds ratio (OR) with $95 \%$ confidence intervals (CI); for continuous data, we calculated mean difference (MD) or standardized mean difference (SMD) with $95 \% \mathrm{CI}$, depending on whether the same scale was used to measure an outcome. Analyses were performed using the software Review Manager (RevMan version 5.4; Cochrane Collaboration, 2020). We used a fixed-effects model, and the level of statistical significance was set at $\mathrm{P}<0.05$ (two-sided). If both data from the baseline and endpoint scores were available for continuous data, we used the change from baseline scores. Missing data were obtained using graphical software (WebPlotDigitizer; Rohatgi, 2015) or other methods $(28,29)$.

We quantified statistical heterogeneity using the $\mathrm{I}^{2}$ statistic; a $0 \%$ value was considered to indicate no heterogeneity, and higher values of $25 \%, 50 \%$, and $75 \%$ represented increasing levels of low, moderate, and high heterogeneity, respectively. An $\mathrm{I}^{2}<50 \%$ was considered as acceptable. If we detected high heterogeneity, we conducted subgroup or sensitivity analysis, and then the randomeffects model would be used $(28,30)$. Where sufficient 
studies were present, we planned to assess publication bias by examining the symmetry of the funnel plot (28).

\section{Assessment of the certainty of evidence}

We assessed the certainty of evidence using the Grading of Recommendations Assessment, Development, and Evaluation (GRADE) approach (31). Two researchers (Shi and Wang) with experience in using GRADE rated each domain for each outcome separately and resolved discrepancies by consensus.

\section{Results}

\section{Literature search}

We identified 10,182 references from the databases, and three records from additional searches. A total of 3,059 records were excluded as duplicates. After screening the titles and abstracts, we selected 136 studies for full-text review. Finally, a total of 10 studies (five RCTs and five NRSIs) involving 480 patients were included (see Figure 1) (22,32-40).

\section{Study and patient characteristics}

Characteristics of the included studies and patients are illustrated in Table 1. These studies were published between 2005 and 2020, and the sample size ranged from 18 to 139, of which, sildenafil (20 mg/TID) was all administered orally. Most studies recruited participants with WHO functional class II and III. The etiologies of the majority of patients were idiopathic $\mathrm{PAH}$, and $\mathrm{PAH}$ associated with CTD and CHD.

\section{Risk of bias in the included studies}

For the five RCTs, we assessed random sequence generation, allocation concealment, blinding of participants and personnel, and blinding of outcomes as low risk for only one study (36). Galiè 2005 (32), Pepke-Zaba 2008 (33), Xu 2013 (37), and Webb 2015 (39) were at unclear risk, as they did not report the relevant methods. As for incomplete outcome data and selective reporting, all studies were assessed as low risk. In the domain of other potential sources of bias, four studies $(32,33,36,39)$ received funding from Pfizer and one contained error in data (37), so we rated all of them at high risk. For the five NRSIs, four $(22,34,38,40)$ were assessed as moderate risk and one (35) was serious risk. Details are shown in Tables S1,S2.

\section{Certainty of evidence in the included studies}

The results of meta-analysis are presented in the following sections. The quality of evidence according to GRADE for each outcome ranged between very low and moderate. Factors contributing to the downgrading of the quality of evidence included risk of bias, inconsistency or imprecision (due to limitations in study design, wide CI or relatively small sample size, and substantial heterogeneity), whereas for some outcomes we were able to upgrade the quality due to the large magnitude of effect. Details are available in Table S3.

\section{Clinical outcomes}

\section{MWD}

Six studies $(22,32-35,38)$ (two RCTs and four NRSIs) evaluated the 6MWD. Two studies $(32,33)$, which only reported the $\mathrm{P}$ values and $99 \%$ CI with significant improvement in 6MWD were excluded from the pooled analysis. Compared with symptomatic treatment, sildenafil yielded greater improvement in 6MWD $(\mathrm{MD}=57.68$ meters, $95 \%$ CI: 41.55 to 73.81 , low-quality evidence). There was no significant heterogeneity between the trials $\left(\mathrm{I}^{2}=39 \%\right.$, Figure 2).

\section{Dyspnoea score}

Three studies $(32,34,35)$ (one RCT and two NRSIs) evaluated the dyspnoea score based on Borg scale. One study (32), which only reported that the change from baseline did not differ significantly from that in the placebo group, with no other data available, was excluded from the pooled analysis. Compared to symptomatic treatment, sildenafil was associated with a significant decrease (reflecting improvement) in the dyspnoea score $[\mathrm{MD}=-0.99$ points, $95 \% \mathrm{CI}:-1.45$ to -0.53 , very low-quality evidence]. There was no heterogeneity between the trials $\left(\mathrm{I}^{2}=0 \%\right.$, Figure 3).

\section{WHO functional class}

Four studies $(22,32,34,35)$ (one RCT and three NRSIs) evaluated the WHO functional class. We described them in narrative form because most data were missing for metaanalysis (Table 2). In general, compared to placebo or symptomatic treatment, the total number of patients with WHO class III and IV in the sildenafil group exhibited an 

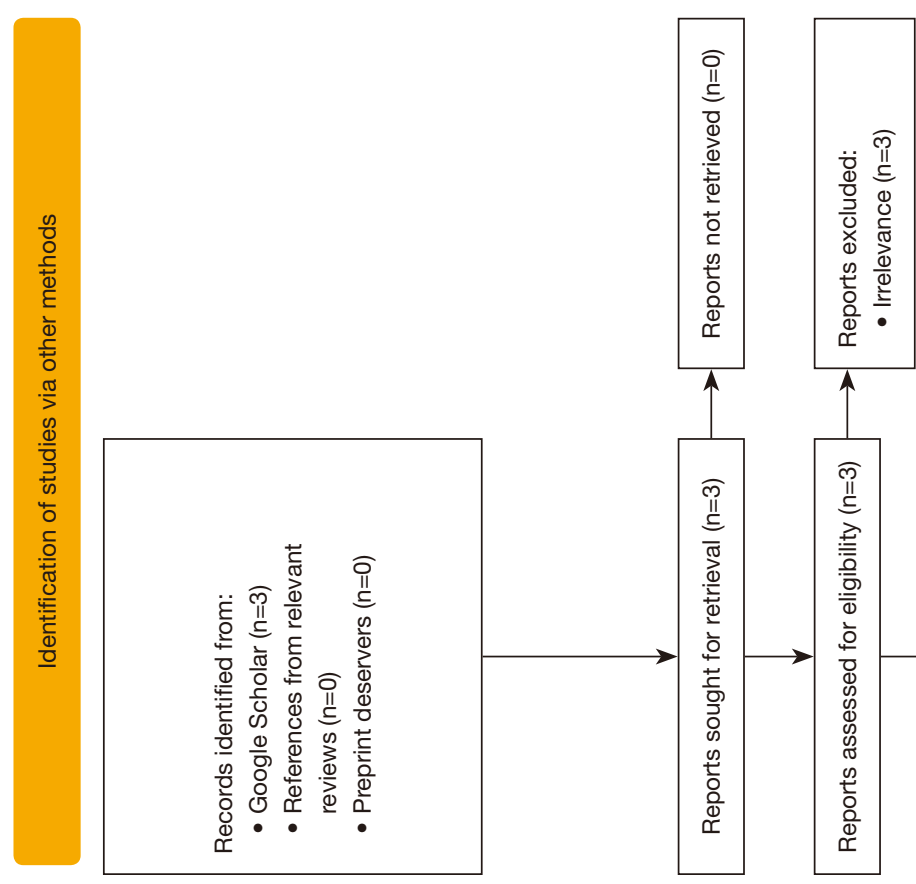

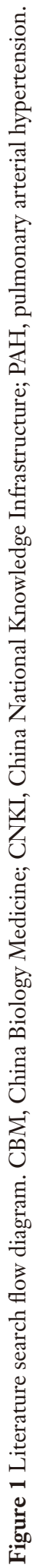


Table 1 Baseline characteristics of included studies

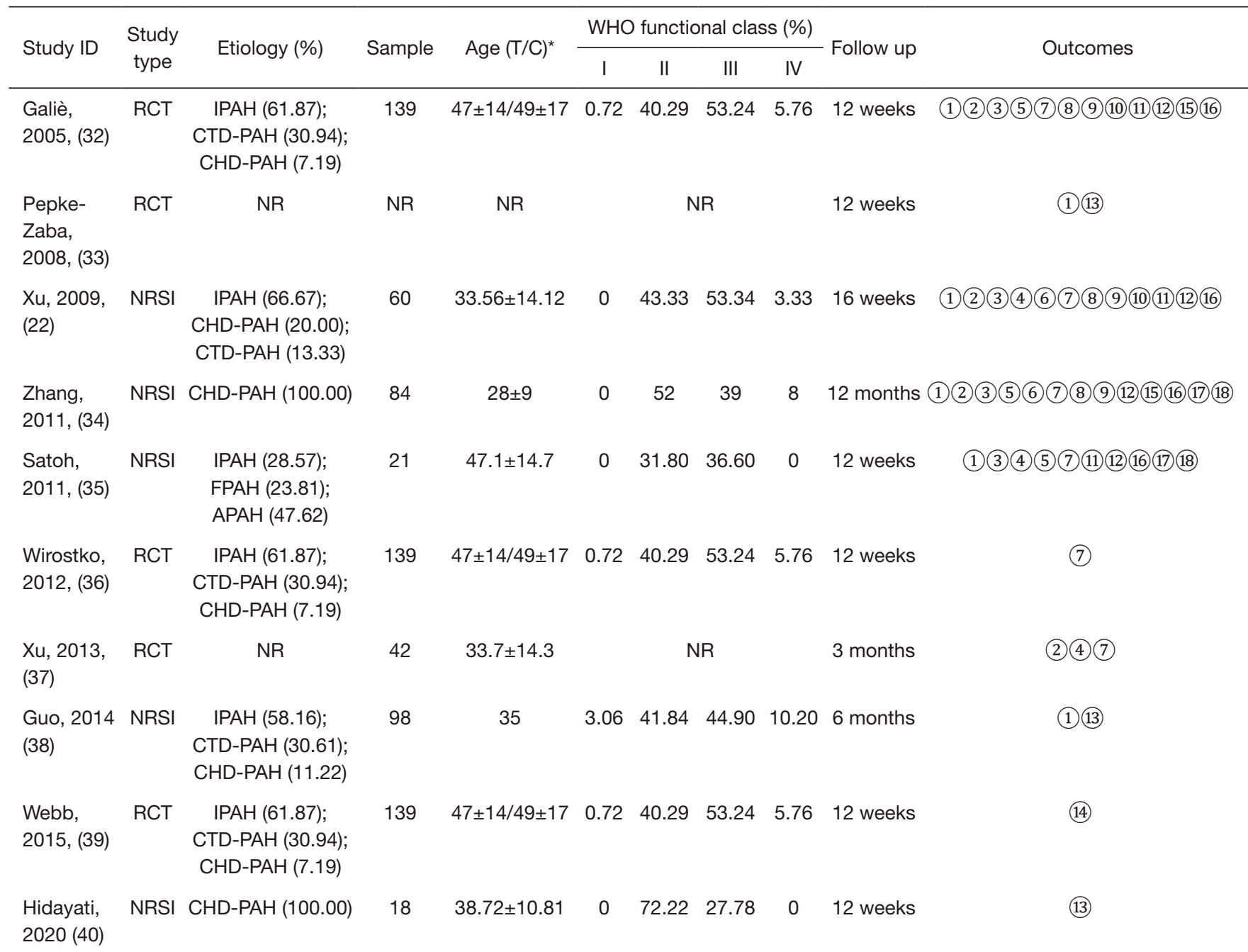

*, ages were reported as mean \pm standard deviation. Outcomes: (1) 6-minute walk distance; (2) mean pulmonary artery pressure; (3) World Health Organization (WHO) functional class; (4) level of brain natriuretic peptide; (5) dyspnoea score on Borg scale; (6) systemic arterial oxygen saturation; (7) adverse events; (8) mortality; (9) clinical worsening; (10) pulmonary vascular resistance; (11) cardiac index; (12) right atrial pressure; (13) quality of life; (14) renal function; (15) hospitalization; 16 heart rate; 17 pulmonary capillary wedge pressure; 18 systemic vascular resistance index. RCT, randomized controlled trial; NRSI, non-randomized studies of interventions; IPAH, idiopathic pulmonary arterial hypertension; CTD-PAH, connective-tissue disease-pulmonary arterial hypertension; CHD-PAH, congenital heart diseasepulmonary arterial hypertension; FPAH, familial pulmonary arterial hypertension; APAH, associated with pulmonary arterial hypertension; $\mathrm{NR}$, not reported; W, week; M, month; T, treatment; C, control.

overall declining trend (reflecting improvement).

\section{Level of BNP}

Three studies $(22,35,37)$ (one RCT and two NRSIs) evaluated the level of BNP. One study (35) that only reported plasma BNP decreased from baseline was excluded from the pooled analysis. Compared to the placebo or symptomatic treatment, sildenafil was associated with a decrease in level of BNP (MD =-86.16 pg /mL, 95\% CI:
-103.39 to -68.93 , very low-quality evidence). There was no significant heterogeneity between the trials $\left(I^{2}=14 \%\right.$, Figure 4).

\section{Mean PAP}

Four studies $(22,32,34,37)$ (two RCTs and two NRSIs) evaluated the mean PAP. Compared to the placebo, sildenafil was associated with a greater reduction in the mean PAP (MD $=-4.13 \mathrm{mmHg}$, 95\% CI: -6.52 to -1.74 , 


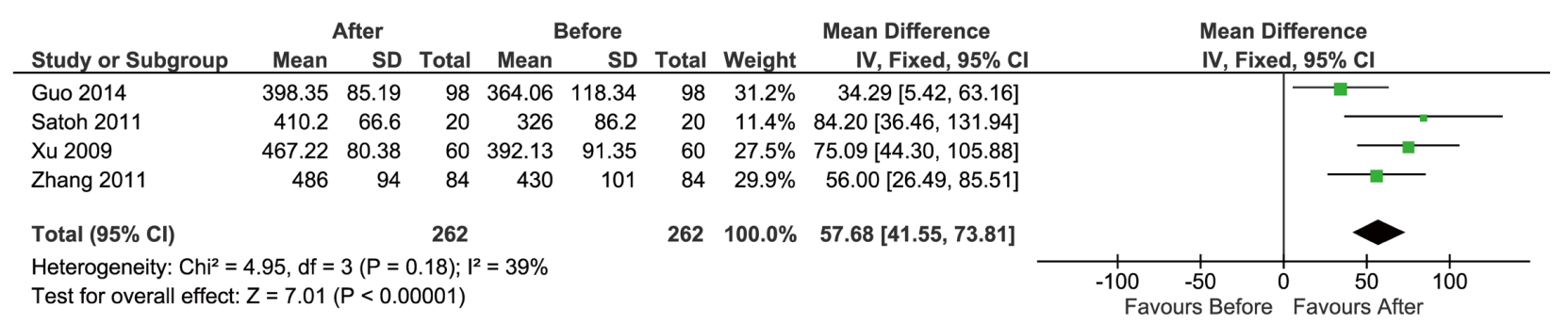

Figure 2 Forest plot of 6-minute walk distance between sildenafil with symptomatic treatment. CI, confidence interval; SD, standard deviation.

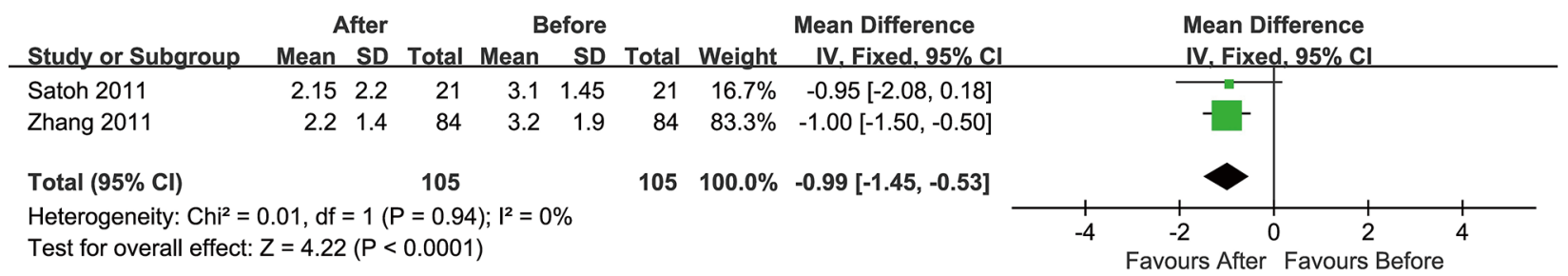

Figure 3 Forest plot of dyspnoea score between sildenafil with symptomatic treatment. CI, confidence interval; SD, standard deviation.

Table 2 Improvement in World Health Organization functional class

\begin{tabular}{lccc}
\hline Study ID & Study type & Placebo/before & Sildenafil/after \\
\hline Galiè, 2005, (32) & RCT & $\begin{array}{c}\text { Patients with an improvement of at least one } \\
\text { functional class were } 7 \%\end{array}$ & $\begin{array}{c}\text { Patients with an improvement of at least } \\
\text { one functional class were 28\% }\end{array}$ \\
Xu, 2009, (22) & NRSI & I: 0; II: 26; III: 32; IV: 2 & I: 6; II: 42; III: 12; IV: 0 \\
Zhang, 2011, (34) & NRSI & I: 0; II: 44; III: 33; IV: 7 & I: 7; II: 68; III: 8; IV: 1 \\
Satoh, 2011, (35) & NRSI & I: 0; II: 7; III: 14; IV: 0 & I: 1 ; II: 11; III: 9; IV: 0
\end{tabular}

$\mathrm{RCT}$, randomized controlled trial; NRSI, non-randomized studies of interventions; NR, not reported.

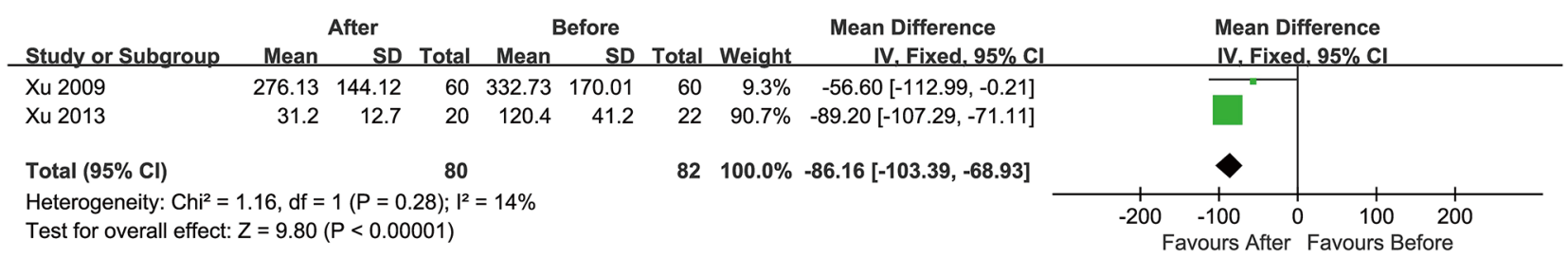

Figure 4 Forest plot of brain natriuretic peptide between sildenafil with placebo or symptomatic treatment. CI, confidence interval; SD, standard deviation.

very low-quality evidence). There was considerable heterogeneity between the trials $\left(\mathrm{I}^{2}=89 \%\right.$, Figure 5). We conducted sensitivity analysis by excluding one study (37), which involved surgery with high risk of bias. The results showed that sildenafil reduced the mean PAP (MD
$=-2.70 \mathrm{mmHg}, 95 \% \mathrm{CI}:-5.26$ to -0.14$)$. Compared to symptomatic treatment, sildenafil could reduce the mean PAP, and no statistically significant difference was observed $(\mathrm{MD}=-4.90 \mathrm{mmHg}, 95 \% \mathrm{CI}:-10.36$ to 0.55 , low-quality evidence; Figure 6). 


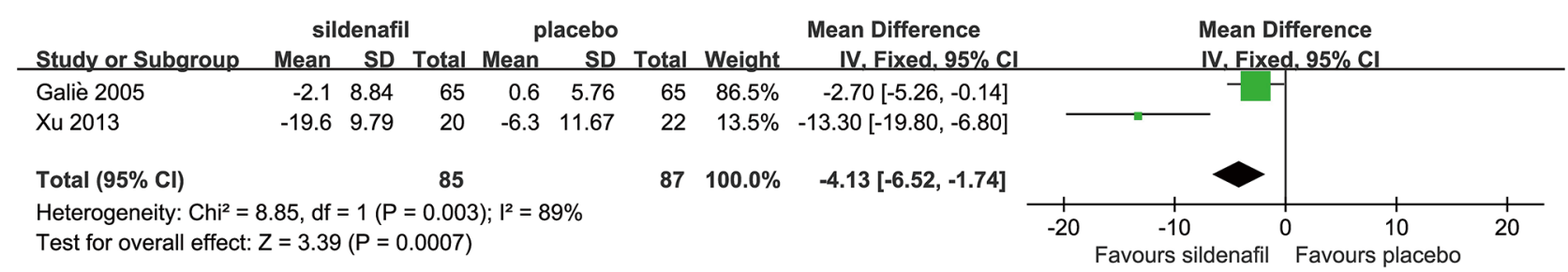

Figure 5 Forest plot of reduction in mean pulmonary artery pressure between sildenafil with placebo. CI, confidence interval; SD, standard deviation.

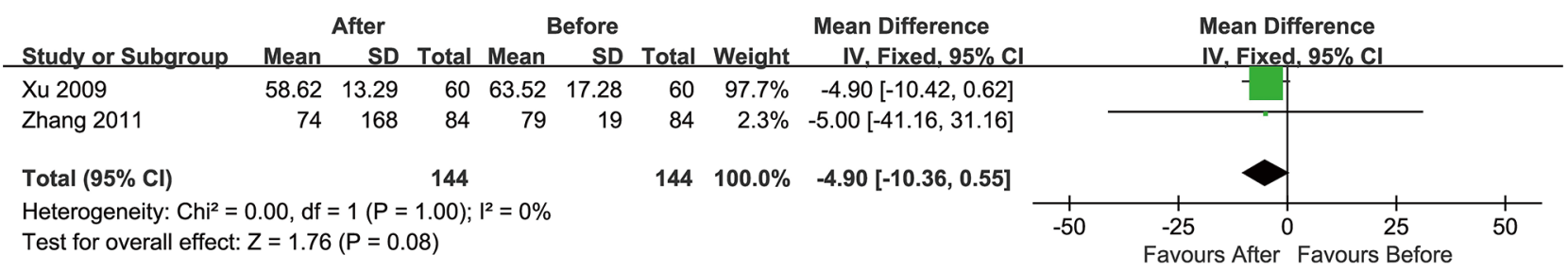

Figure 6 Forest plot of mean pulmonary artery pressure between sildenafil with symptomatic treatment. CI, confidence interval; SD, standard deviation.

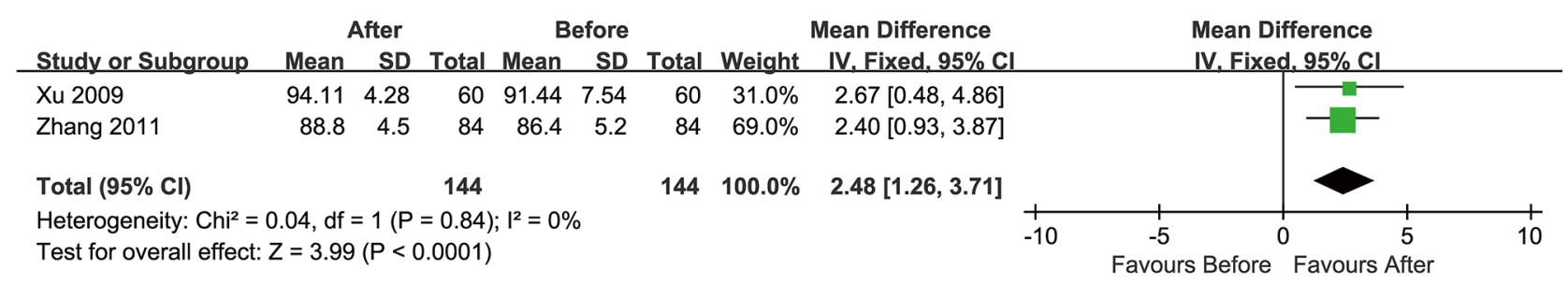

Figure 7 Forest plot of systemic arterial oxygen saturation between sildenafil with symptomatic treatment. CI, confidence interval; SD, standard deviation.

\section{Systemic arterial oxygen saturation}

Two NRSIs $(22,34)$ evaluated the systemic arterial oxygen saturation. Compared with symptomatic treatment, patients who received sildenafil had a higher level of systemic arterial oxygen saturation ( $\mathrm{MD}=2.48 \%, 95 \% \mathrm{CI}: 1.26$ to 3.71 , lowquality evidence). There was no heterogeneity between the trials $\left(\mathrm{I}^{2}=0 \%\right.$, Figure 7$)$.

\section{Haemodynamic parameters other than mean PAP}

Two studies $(22,32)$ (one RCT and one NRSI) evaluated the PVR. Compared to the placebo, sildenafil was associated with a greater reduction in PVR $\left(\mathrm{MD}=-171.00 \mathrm{dyn} \cdot \mathrm{s} \cdot \mathrm{cm}^{-5}\right.$, 95\% CI: -311.49 to -30.51 , moderate-quality evidence). Moreover, compared to symptomatic treatment, sildenafil could decrease PVR, although the difference was not statistically significant (MD $=-1.02$ Wood Units, 95\% CI: -3.73 to 1.69 , low-quality evidence).

Four studies $(22,32,34,35)$ (one RCT and three NRSIs) evaluated the RAP. Compared to symptomatic treatment, the results showed that sildenafil therapy decreased RAP (MD $=-1.17 \mathrm{mmHg}, 95 \% \mathrm{CI}:-2.14$ to -0.20 , very lowquality evidence). Furthermore, compared to the placebo, reduction in RAP was also observed with no statistically significant difference found ( $\mathrm{MD}=-1.10 \mathrm{mmHg}, 95 \% \mathrm{CI}$ : -2.73 to 0.53 , moderate-quality evidence).

Three studies $(22,32,35)$ (one RCT and two NRSIs) evaluated cardiac index. Compared to symptomatic treatment, the use of sildenafil improved the level of cardiac index $\left[\mathrm{MD}=0.35 \mathrm{~L} /\left(\mathrm{min} \cdot \mathrm{m}^{2}\right), 95 \% \mathrm{CI}: 0.07\right.$ to 0.63 , very low-quality evidence]. However, no statistically significant 
difference was observed in the reduction of cardiac index $\left[\mathrm{MD}=0.23 \mathrm{~L} /\left(\mathrm{min} \cdot \mathrm{m}^{2}\right), 95 \% \mathrm{CI}:-0.18\right.$ to 0.64 , moderatequality evidence] between sildenafil and placebo.

\section{Adverse events}

Six studies $(22,32,34-37)$ (two RCTs and three NRSIs) evaluated adverse events. One study that reported adverse events with no data available was excluded from the pooled analysis (37). Compared to symptomatic treatment or placebo, there was no statistically significant difference in the risk of headache, flushing, dyspepsia, diarrhea, limb pain, or skin rash (Figure 8). No statistically significant difference was also observed in blood pressure (systolic and diastolic) and ocular safety (including change in intraocular pressure and risk of deterioration in visual acuity). In general, sildenafil was mild and well tolerated in most patients. The overall quality of evidence ranged between low and moderate.

\section{Long-term prognosis}

Four studies reported outcomes related to long-term prognosis. Three studies $(22,32,34)$ (one RCT and two NRSIs) evaluated mortality (OR $=1.01,95 \%$ CI: 0.06 to 16.55 , very low-quality evidence) and the incidence of clinical worsening (OR $=3.36,95 \% \mathrm{CI}$ : 0.19 to 60.54 , very low-quality evidence), between sildenafil and symptomatic treatment/placebo, no statistically significant difference was observed.

Three studies $(33,38,40)$ evaluated quality of life. There was a statistically significant improvement in the Short Form (SF)-36 domains of physical functioning, general health, and vitality for sildenafil-treated participants when compared to the placebo. Statistically significant improvements were also observed in terms of current health status and utility index in the EuroQol five dimensions (EQ-5D) and EuroQol visual analogue scale (EQ-VAS) questionnaires. The results of Webb 2015 (39) showed that sildenafil treatment improved kidney function compared to the placebo, but the difference was not statistically significant.

In addition, there was no significant difference in hospitalization, heart rate, pulmonary capillary wedge pressure, and systemic vascular resistance index compared to the placebo or symptomatic treatment.

\section{Publication bias}

Due to insufficient studies for each outcome, we were unable to evaluate publication bias.

\section{Discussion}

Our systematic review identified a total of 10 studies. Compared to the placebo or symptomatic treatment, the use of sildenafil (20 mg/TID) showed a clear statistical and clinical benefit for adult Asian $\mathrm{PAH}$ patients in terms of 6MWD, mean PAP, systemic arterial oxygen saturation, dyspnoea score on the Borg scale, level of BNP, and PVR. As for safety, clinicians should be aware of headache, flushing, dyspepsia, and diarrhea, which were usually relatively mild.

According to existing guidelines (3,17-19), $\mathrm{PAH}$ patients should be clearly diagnosed as soon as possible and establish treatment strategies on the basis of risk stratification (41). During this process, making full use of targeted drugs is crucial. Research in recent years has produced various therapeutic options for its clinical management $(14,42)$. Currently approved therapies for $\mathrm{PAH}$ act via three distinct pathways, of which, the NO pathway is one of the key pathways underlying the pathophysiology of PAH, and found to interact with other crucial pathways (42). As one of five classes of drugs now available for PAH, phosphodiesterase-5 (PDE5) inhibitors include sildenafil, tadalafil, and vardenafil $(4,12,13)$. Among these, both the FDA and EMA recommended that sildenafil be orally administered at a dose of $20 \mathrm{mg} / \mathrm{TID}$. Although increasing evidence has suggested that sildenafil therapy is beneficial $(21,22,43-46)$, the dose varies greatly. A Cochrane systematic review published in 2019 indicated that sildenafil has a better therapeutic effect, with a lower incidence of adverse events compared to the placebo (16). However, sildenafil in the included PAH trials was prescribed in eight hourly divided doses, with dosages ranging from 20 to $100 \mathrm{mg} / \mathrm{TID}$ (16).

In this study, we focused on $20 \mathrm{mg} / \mathrm{TID}$, and included participants who were mainly idiopathic $\mathrm{PAH}$, as well as CTD and CHD-related PAH. The results of $6 \mathrm{MWD}$, mean PAP, dyspnoea score, and level of BNP were similar to those identified in other systematic reviews $(16,21,22,43-46)$. As an important indicator for severity evaluation and prognosis (47), previous studies have shown that there is a significant improvement in WHO functional class favouring sildenafil comparing to the placebo (16). However, our systematic review demonstrated that four studies assessed this, but with too much data was missing to combine in a meta-analysis. On the other hand, we identified gaps in the existing literature that limited our conclusions. The included studies focused less on long-term outcomes, and 


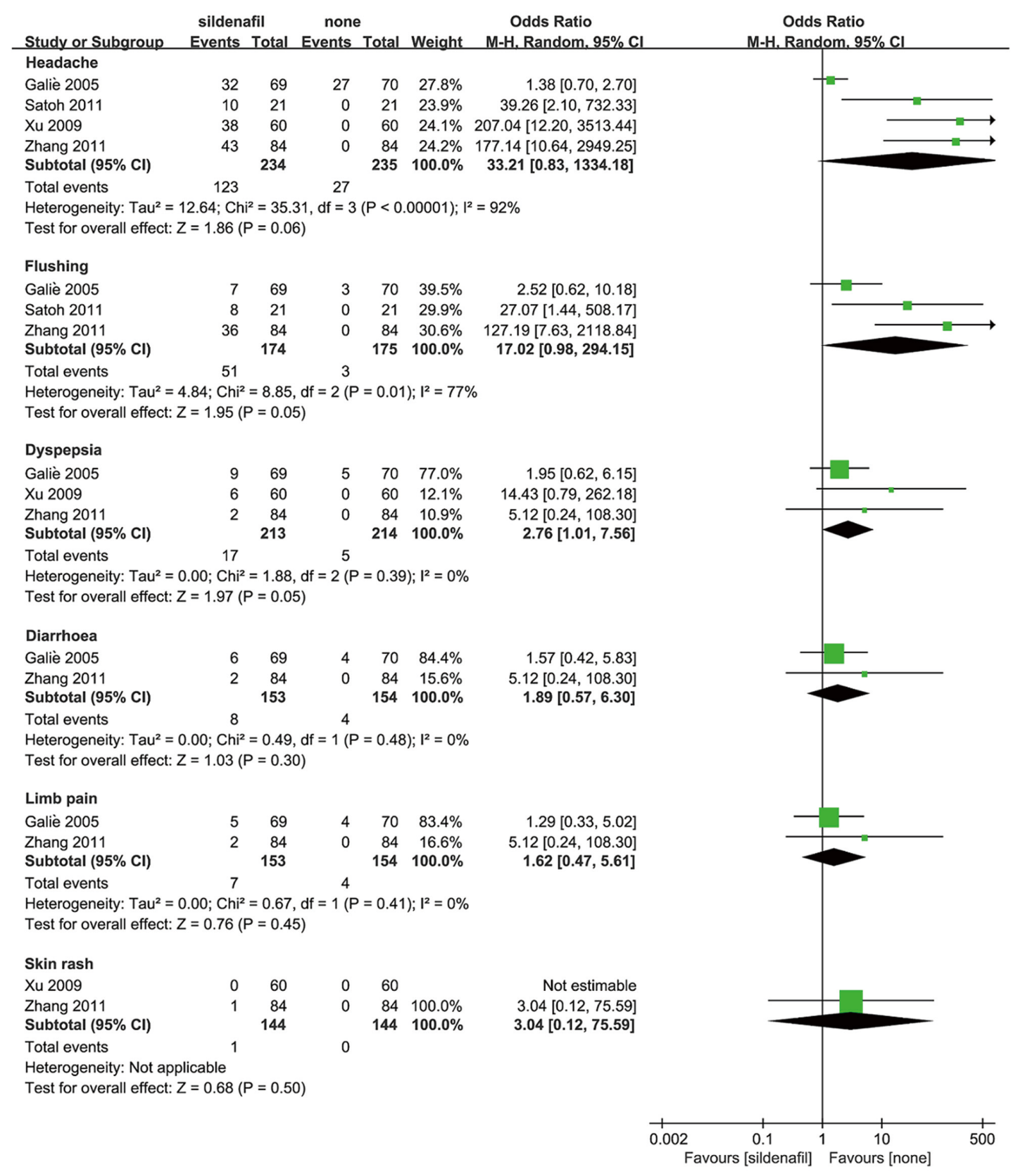

Figure 8 Forest plot of adverse events. CI, confidence interval.

did not pay attention to pharmacoeconomics. Comparing to the placebo, $\mathrm{PAH}$ participants treated with sildenafil have been shown to be $23 \%$ less likely to die (16), but results from our study indicated that only three studies analyzed mortality, and a non-statistically significant difference was found. Also, only one study assessed quality of life. Further trials are needed to evaluate the effectiveness of sildenafil (20 mg/TID) on long-term outcomes.
In terms of safety, one of the most frequent concerns with the use of PDE5 is the risk of hypotension (15). Although we found no statistically significant difference in systolic and diastolic blood pressure compared to symptomatic treatment or placebo, nitrates should not be used in combination with sildenafil, especially be prudent in patients with low systemic blood pressure or presyncope $(4,15)$.

Considering that sildenafil has been poorly studied 
for the treatment of adult PAH patients in Asia, we also included the Sildenafil Use in Pulmonary Arterial Hypertension (SUPER) study $(32,33,36,39)$, a Pfizersponsored randomized trial. However, for the final included studies, the total sample size is still very small and there is unclear risk of bias for methodology, especially in the domains of randomization, allocation concealment, and blindness. So far, several lines of evidence have strongly suggested that targeting the NO pathway might be the strategy with the most potential. A recent investigation also found that higher adherence to PDE5 in patients with $\mathrm{PAH}$ is associated with a lower risk of hospitalization and rehospitalization (48). Therefore, we suggest the following for further research: (I) conducting high-quality studies at the recommended dose of $20 \mathrm{mg} / \mathrm{TID}$; (II) trials should measure outcomes which are clinically relevant (e.g., mortality, quality of life, and clinical worsening) so that the long-term effects can be established; and (III) attach importance to the real-world data and evaluation of pharmacoeconomics.

To our knowledge, this study is the first systematic review to summarize the evidence for the effectiveness and safety of sildenafil in patients with $\mathrm{PAH}$ at the recommended dose of $20 \mathrm{mg} / \mathrm{TID}$, which is of hugely important for clinicians and patients. We focused on Asian adults and included Chinese studies to identify research gap. We also focused on multiple outcome measures (both short- and longterm). This study has also several limitations that should be noted. Firstly, the missing data for some outcomes and small participant samples might undermine the real effect of treatment. Secondly, we excluded studies other than those published in English and Chinese, as well as conference abstracts for which the full text could not be obtained, and thus, some degree of publication bias may exist. Thirdly, we found one study (37) in which PAP was measured by echocardiography, and although it was not right cardiac catheterization, we included it and synthesized its data in the final meta-analysis.

\section{Conclusions}

Although data comparing sildenafil $(20 \mathrm{mg} / \mathrm{TID})$ in adult Asian PAH patients is limited by the small number and sample size of included trials, our study provides conclusive evidence that sildenafil ( $20 \mathrm{mg} / \mathrm{TID})$ is effective and safe. Statistically significant improvements in exercise capacity, cardio-pulmonary function, and haemodynamics were observed, with mild to moderate adverse reactions and good tolerance. We suggest future trials should include a large sample, be of high methodological quality, and pay more attention to the long-term prognosis.

\section{Acknowledgments}

We thank Qi Zhou, who is from Evidence-based Medicine Center, School of Basic Medical Sciences of Lanzhou University, for providing guidance and comments to our systematic review.

Funding: This study was funded by Viatris China. The study sponsor participated in the design, with no involvement in collection, analysis, and interpretation of the data, in the writing of the article, or in the decision to submit for publication.

\section{Footnote}

Reporting Checklist: The authors have completed the PRISMA reporting checklist. Available at https://apm. amegroups.com/article/view/10.21037/apm-21-3979/rc

Conflicts of Interest: All authors have completed the ICMJE uniform disclosure form (available at https://apm. amegroups.com/article/view/10.21037/apm-21-3979/coif). All authors report that this study was funded by Viatris China. The authors have no other conflicts of interest to declare.

Ethical Statement: The authors are accountable for all aspects of the work in ensuring that questions related to the accuracy or integrity of any part of the work are appropriately investigated and resolved.

Open Access Statement: This is an Open Access article distributed in accordance with the Creative Commons Attribution-NonCommercial-NoDerivs 4.0 International License (CC BY-NC-ND 4.0), which permits the noncommercial replication and distribution of the article with the strict proviso that no changes or edits are made and the original work is properly cited (including links to both the formal publication through the relevant DOI and the license). See: https://creativecommons.org/licenses/by-nc-nd/4.0/.

\section{References}

1. Hoeper MM, Bogaard HJ, Condliffe R, et al. Definitions and diagnosis of pulmonary hypertension. J Am Coll 
Cardiol 2013;62:D42-50.

2. Hoeper MM, Humbert M, Souza R, et al. A global view of pulmonary hypertension. Lancet Respir Med 2016;4:306-22.

3. McLaughlin VV, Archer SL, Badesch DB, et al. ACCF/ AHA 2009 expert consensus document on pulmonary hypertension: a report of the American College of Cardiology Foundation Task Force on Expert Consensus Documents and the American Heart Association: developed in collaboration with the American College of Chest Physicians, American Thoracic Society, Inc., and the Pulmonary Hypertension Association. Circulation 2009;119:2250-94. Erratum in: Circulation 2009;120:e13.

4. Archer SL, Michelakis ED. Phosphodiesterase type 5 inhibitors for pulmonary arterial hypertension. N Engl J Med 2009;361:1864-71.

5. Badesch DB, Raskob GE, Elliott CG, et al. Pulmonary arterial hypertension: baseline characteristics from the REVEAL Registry. Chest 2010;137:376-87.

6. Hoeper MM, Simon R Gibbs J. The changing landscape of pulmonary arterial hypertension and implications for patient care. Eur Respir Rev 2014;23:450-7.

7. Peacock AJ, Murphy NF, McMurray JJ, et al. An epidemiological study of pulmonary arterial hypertension. Eur Respir J 2007;30:104-9.

8. Humbert M, Sitbon O, Chaouat A, et al. Pulmonary arterial hypertension in France: results from a national registry. Am J Respir Crit Care Med 2006;173:1023-30.

9. Escribano-Subias P, Blanco I, López-Meseguer M, et al. Survival in pulmonary hypertension in Spain: insights from the Spanish registry. Eur Respir J 2012;40:596-603.

10. Delcroix M, Howard L. Pulmonary arterial hypertension: the burden of disease and impact on quality of life. Eur Respir Rev 2015;24:621-9.

11. McLaughlin VV, Shillington A, Rich S. Survival in primary pulmonary hypertension: the impact of epoprostenol therapy. Circulation 2002;106:1477-82.

12. Montani D, Chaumais MC, Guignabert C, et al. Targeted therapies in pulmonary arterial hypertension. Pharmacol Ther 2014;141:172-91.

13. Safdar Z. Targeted oral therapies in the treatment of pulmonary arterial hypertension. Clin Drug Investig 2010;30:811-26.

14. Zolty R. Pulmonary arterial hypertension specific therapy: The old and the new. Pharmacol Ther 2020;214:107576.

15. Humbert M, Sitbon O, Simonneau G. Treatment of pulmonary arterial hypertension. $\mathrm{N}$ Engl J Med 2004;351:1425-36.
16. Barnes H, Brown Z, Burns A, et al. Phosphodiesterase 5 inhibitors for pulmonary hypertension. Cochrane Database Syst Rev 2019;1:CD012621.

17. Pulmonary Vascular Disease Group, Cardiovascular Branch, Chinese Medical Association. Chinese Guidelines for the Diagnosis and Treatment of Pulmonary Hypertension 2021. National Medical Journal of China 2021;101:11-51.

18. Galiè N, Humbert M, Vachiery JL, et al. 2015 ESC/ERS Guidelines for the Diagnosis and Treatment of Pulmonary Hypertension. Rev Esp Cardiol (Engl Ed) 2016;69:177.

19. Klinger JR, Elliott CG, Levine DJ, et al. Therapy for Pulmonary Arterial Hypertension in Adults: Update of the CHEST Guideline and Expert Panel Report. Chest 2019;155:565-86.

20. He CJ, Chen SJ, Wang J, et al. Efficacy and safety of phosphodiesterase type-5 inhibitors for pulmonary arterial hypertension: A meta-analysis focusing on 6MWD. Pulm Pharmacol Ther 2015;32:24-8.

21. Liu HL, Chen XY, Li JR, et al. Efficacy and Safety of Pulmonary Arterial Hypertension-specific Therapy in Pulmonary Arterial Hypertension: A Meta-analysis of Randomized Controlled Trials. Chest 2016;150:353-66.

22. Xu XQ, Jing ZC, Zhang JH, et al. The efficacy and safety of sildenafil in Chinese patients with pulmonary arterial hypertension. Hypertens Res 2009;32:911-5.

23. Page MJ, McKenzie JE, Bossuyt PM, et al. The PRISMA 2020 statement: an updated guideline for reporting systematic reviews. BMJ 2021;372:n71.

24. Rethlefsen ML, Kirtley S, Waffenschmidt S, et al. PRISMA-S: an extension to the PRISMA Statement for Reporting Literature Searches in Systematic Reviews. Syst Rev 2021;10:39.

25. Li L, Tian J, Tian H, et al. Network meta-analyses could be improved by searching more sources and by involving a librarian. J Clin Epidemiol 2014;67:1001-7.

26. Higgins JP, Altman DG, Gøtzsche PC, et al. The Cochrane Collaboration's tool for assessing risk of bias in randomised trials. BMJ 2011;343:d5928.

27. Sterne JA, Hernán MA, Reeves BC, et al. ROBINS-I: a tool for assessing risk of bias in non-randomised studies of interventions. BMJ 2016;355:i4919.

28. Higgins J, Thomas J, Chandler J, et al. editors. Cochrane Handbook for Systematic Reviews of Interventions version 6.2 (updated February 2021). Cochrane, 2021. Available online: www.training.cochrane.org/handbook

29. Furukawa TA, Barbui C, Cipriani A, et al. Imputing missing standard deviations in meta-analyses can provide 
accurate results. J Clin Epidemiol 2006;59:7-10.

30. DerSimonian R, Kacker R. Random-effects model for meta-analysis of clinical trials: an update. Contemp Clin Trials 2007;28:105-14.

31. Guyatt G, Oxman AD, Akl EA, et al. GRADE guidelines: 1. Introduction-GRADE evidence profiles and summary of findings tables. J Clin Epidemiol 2011;64:383-394.

32. Galiè N, Ghofrani HA, Torbicki A, et al. Sildenafil citrate therapy for pulmonary arterial hypertension. $\mathrm{N} \mathrm{Engl} \mathrm{J}$ Med 2005;353:2148-57.

33. Pepke-Zaba J, Gilbert C, Collings L, et al. Sildenafil improves health-related quality of life in patients with pulmonary arterial hypertension. Chest 2008;133:183-9.

34. Zhang ZN, Jiang $X$, Zhang R, et al. Oral sildenafil treatment for Eisenmenger syndrome: a prospective, openlabel, multicentre study. Heart 2011;97:1876-81.

35. Satoh T, Saji T, Watanabe H, et al. A phase III, multicenter, collaborative, open-label clinical trial of sildenafil in Japanese patients with pulmonary arterial hypertension. Circ J 2011;75:677-82.

36. Wirostko BM, Tressler C, Hwang LJ, et al. Ocular safety of sildenafil citrate when administered chronically for pulmonary arterial hypertension: results from phase III, randomised, double masked, placebo controlled trial and open label extension. BMJ 2012;344:e554.

37. Xu XL, Qi GR, Lu L, et al. Effects of transcatheter closure and Sildenafil on plasma brain natriuretic peptide in patients with ventricular septal defects combined with moderate-severe pulmonary artery hypertension. Shandong Medical Journal 2013;53:15-7.

38. Guo R, Wang y, Pan L, et al. Effect of sildenafil on pulmonary hypertension and its effect on quality of life. Shandong Medical Journal 2014;54:43-45.

39. Webb DJ, Vachiery JL, Hwang LJ, et al. Sildenafil improves renal function in patients with pulmonary arterial hypertension. Br J Clin Pharmacol 2015;80:235-41.

40. Hidayati F, Gharini PPR, Hartopo AB, et al. The effect of oral sildenafil therapy on health-related quality of life in adults with pulmonary arterial hypertension related to uncorrected secundum atrial septal defect: a quasi experimental study. Health Qual Life Outcomes 2020;18:278.

41. Galiè N, Channick RN, Frantz RP, et al. Risk stratification and medical therapy of pulmonary arterial hypertension. Eur Respir J 2019;53:1801889.

42. Tettey A, Jiang Y, Li X, et al. Therapy for Pulmonary Arterial Hypertension: Glance on Nitric Oxide Pathway. Front Pharmacol 2021;12:767002.

43. Cukier FN, Fernandes RA, Takemoto MLS, et al. Efficacy and Safety of Sildenafil Above $60 \mathrm{mg}$ Daily in Pulmonary Arterial Hypertension Treatment-a Systematic Literature Review. Value Health 2011;14:PA488.

44. Igarashi A, Inoue S, Ishii T, et al. Comparative Effectiveness of Oral Medications for Pulmonary Arterial Hypertension. Int Heart J 2016;57:466-72.

45. Wang $Y$, Zhang X. Efficacy of Sildenafil Therapy in Pulmonary Artery Hypertension: A Meta-Analysis. The Journal of Evidence-Based Medicine 2014;14:160-5.

46. Kuang TG, Wang J, Zhai ZG, et al. Efficacy and safety of sildenafil therapy in pulmonary artery hypertension: a meta-analysis. National Medical Journal of China 2007;87:1021-4.

47. Chinese Society of Cardiology of Chinese Medical Association, Editorial Board of Chinese Journal of Cardiology. Clinical application of six-minute walk distance text. Chinese Journal of Cardiology 2006;34:381-4.

48. Frantz RP, Hill JW, Lickert CA, et al. Medication adherence, hospitalization, and healthcare resource utilization and costs in patients with pulmonary arterial hypertension treated with endothelin receptor antagonists or phosphodiesterase type- 5 inhibitors. Pulm Circ 2020;10:2045894019880086.

(English Language Editor: A. Kassem)
Cite this article as: Shi Q, Wang Z, Yang N, Ma Y, Chen Y, Wei H, Yao H. Sildenafil for adult Asian patients with pulmonary arterial hypertension: a systematic review and metaanalysis. Ann Palliat Med 2022;11(1):339-351. doi: 10.21037/ apm-21-3979 


\section{Supplementary}

\section{Additional file 1 Search Strategies}

\section{MEDLINE}

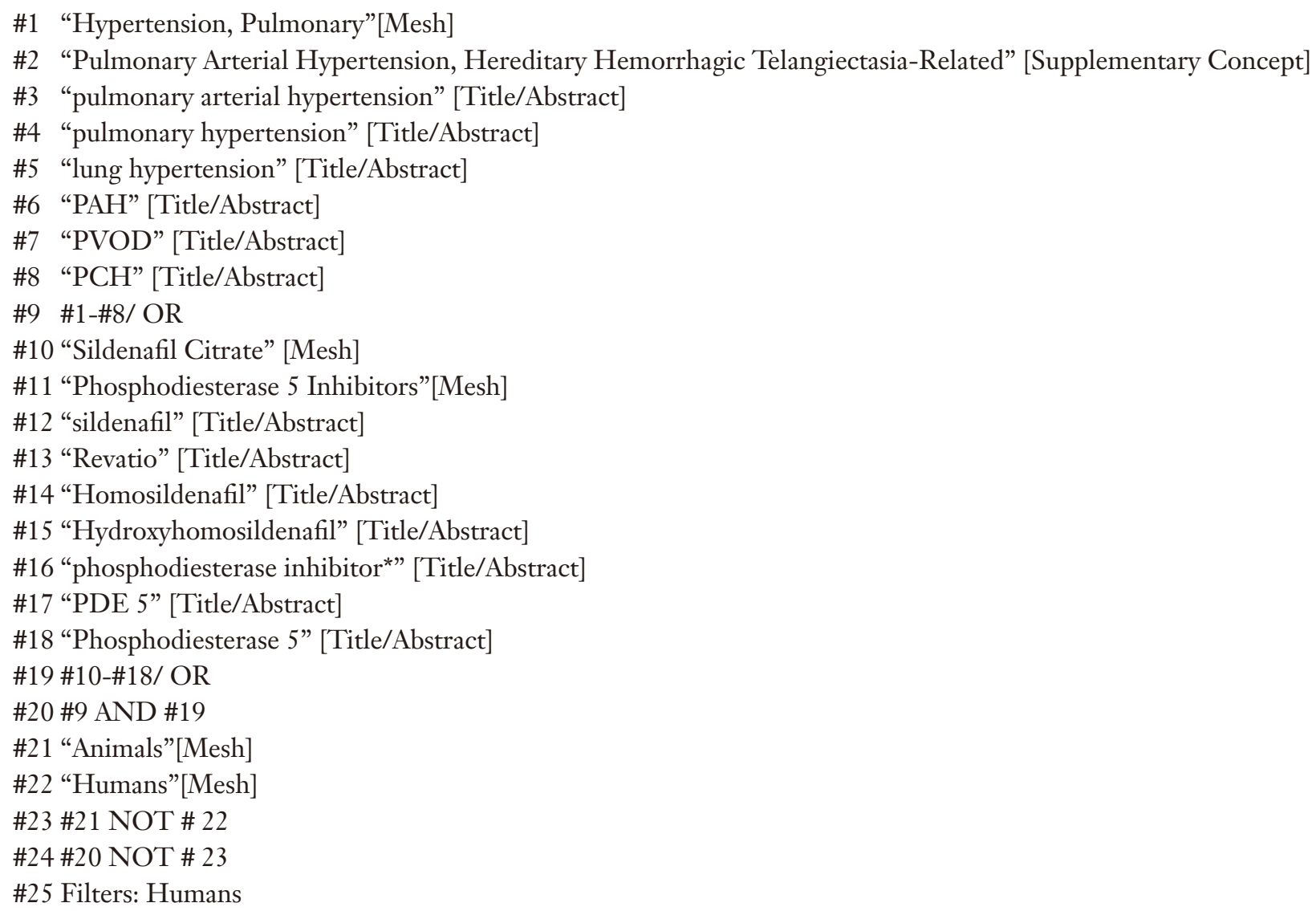

\section{Embase}

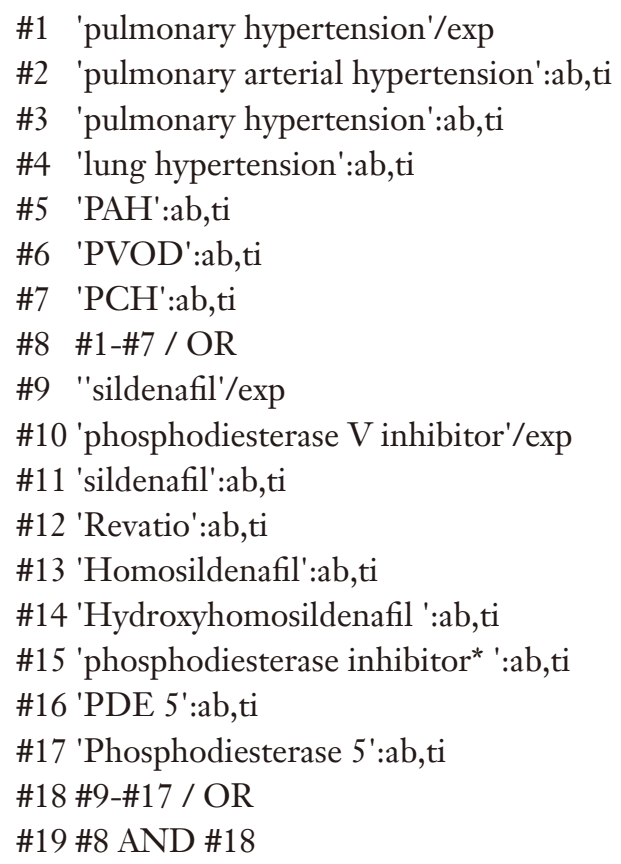


\#20 'animal'/exp

\#21 'human'/exp

\#22 \#20 NOT \# 21

\#23 \#19 NOT \# 22

\#24 [medline]/lim in \#23

\#25 \#23 NOT \#24

\section{Web of science}

\#1 TITLE: "pulmonary arterial hypertension"

\#2 TITLE: "pulmonary hypertension"

\#3 TOPIC: "lung hypertension"

\#4 TITLE: "PAH"

\#5 TOPIC: "PVOD"

\#6 TOPIC: "PCH"

\#7 \#1-\#6/OR

\#8 TOPIC: ("sildenafil")

\#9 TOPIC: ("phosphodiesterase inhibitor")

\#10 TOPIC: ("Revatio")

\#11 TOPIC: ("Homosildenafil")

\#12 TOPIC: ("Hydroxyhomosildenafil")

\#13 TOPIC: ("PDE 5")

\#14 TOPIC: ("Phosphodiesterase 5")

\#15 \#8-\#14 / OR

\#16 \#7 AND \#15

\section{The Cochrane Library}

\#1 MeSH descriptor: [Hypertension, Pulmonary] explode all trees

\#2 “pulmonary arterial hypertension":ti,ab,kw

\#3 “pulmonary hypertension":ti,ab,kw

\#4 "lung hypertension":ti,ab,kw

\#5 "PAH":ti,ab,kw

\#6 "PVOD":ti,ab,kw

\#7 "PCH":ti,ab,kw

\#8 \#1-\#7/ OR

\#9 MeSH descriptor: [Sildenafil Citrate] explode all trees

\#10 MeSH descriptor: [phosphodiesterase 5 inhibitors] explode all trees \#11 "sildenafil": ti, ab, kw

\#12 "phosphodiesterase inhibitor"” : ti, ab, kw

\#13 "Revatio": ti, ab, kw

\#14 "Homosildenafil": ti, ab, kw

\#15 "Hydroxyhomosildenafil": ti, ab, kw

\#16 "PDE 5": ti, ab, kw

\#17 "Phosphodiesterase 5": ti, ab, kw

\#18 \#9-\#17 / OR

\#19 \#8 AND \#18

\section{CNKI}

\#1 主题:(“肺动脉高压”)

\#2 主题:(“肺高压”) 
\#3 \#1-\#2/ OR

\#4 主题:(“西地那非”)

\#5 主题:(“万艾可”)

\#6 主题:(“昔多芬”)

\#7 \#4-\#6/ OR

\#8 \#3 AND \#7

\#9 限定医药卫生

\section{CBM}

\#1 “高血压, 肺性”[不加权 : 扩展 ]

\#2 “肺动脉高压” [ 常用字段 : 智能 ]

\#3 “肺高压”[ 常用字段 : 智能 ]

\#4 \#1-\#3/ OR

\#5 “枸橡酸西地那非” [ 不加权 : 扩展 ]

\#6 “西地那非” [ 常用字段: 智能 ]

\#7 “万艾可” [ 常用字段: 智能]

\#8 “昔多芬” [ 常用字段: 智能]

\#9 \#5-\#8/ OR

\#10 \#4 AND \#9

\section{Wanfang}

\#1 主题:(“肺动脉高压”)

\#2 主题 :(“肺高压”)

\#3 \#1-\#2/ OR

\#4 主题:(“西地那非”)

\#5 主题:(“万艾可”)

\#6 主题:(“昔多芬”)

\#7 \#4-\#6/ OR

\#8 \#3 AND \#7

\#9 限定医药、卫生

\#10 限定万方来源 
Table S1 Risk of bias assessment-the risk of bias of included RCTs

\begin{tabular}{lccccccc}
\hline Study ID & $\begin{array}{c}\text { Random } \\
\text { sequence } \\
\text { generation }\end{array}$ & $\begin{array}{c}\text { Allocation } \\
\text { concealment }\end{array}$ & $\begin{array}{c}\text { Blinding of } \\
\text { participants and } \\
\text { personnel }\end{array}$ & $\begin{array}{c}\text { Blinding of } \\
\text { outcome } \\
\text { assessment }\end{array}$ & $\begin{array}{c}\text { Incomplete } \\
\text { outcome data }\end{array}$ & $\begin{array}{c}\text { Selective } \\
\text { outcome } \\
\text { reporting }\end{array}$ & $\begin{array}{c}\text { Other potential } \\
\text { sources of bias }\end{array}$ \\
\hline Galiè 2005 & Unclear & Unclear & Unclear & Unclear & Low risk & Low risk & High risk \\
Wirostko 2012 & Low risk & Low risk & Low risk & Low risk & Low risk & Low risk & High risk \\
Pepke-Zaba 2008 & Unclear & Unclear & Unclear & Unclear & Low risk & Low risk & High risk \\
Webb 2015 & Unclear & Unclear & Unclear & Unclear & Low risk & Low risk & High risk \\
Xu 2013 & Unclear & Unclear & Unclear & Unclear & Low risk & Low risk & High risk \\
\hline
\end{tabular}

$\mathrm{RCT}$, randomized controlled trial.

Table S2 Risk of bias assessment - the risk of bias of included NRSIs

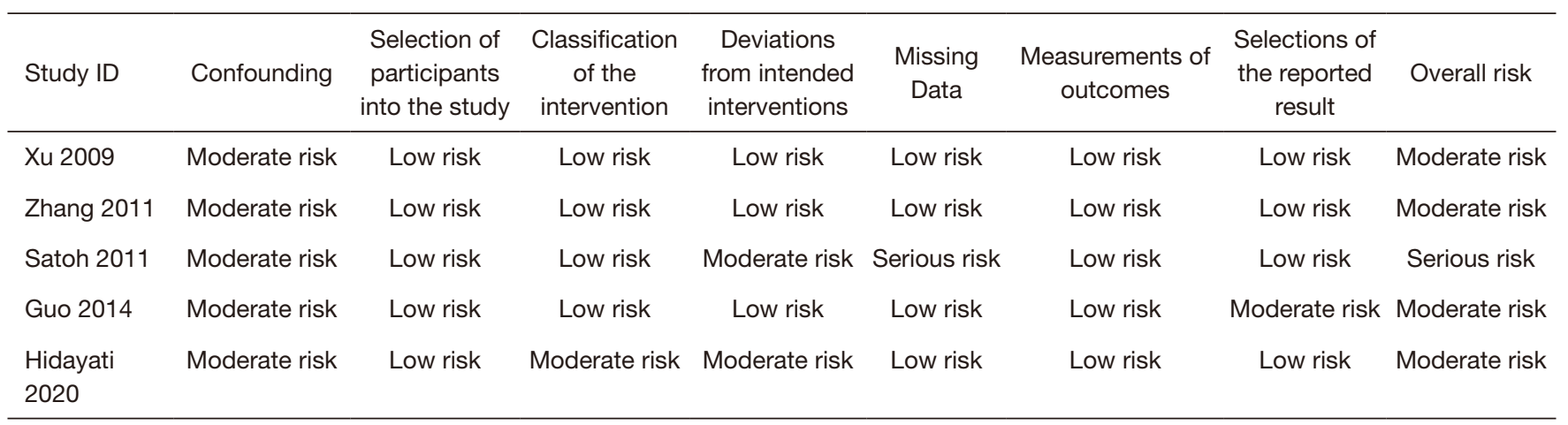

NRSI, Non-Randomized Studies of Interventions. 
Table S3 GRADE evidence profile-summary of Sildenafil for Asian adults with pulmonary arterial hypertension

\begin{tabular}{|c|c|c|c|c|c|c|c|c|c|c|c|c|}
\hline \multirow{2}{*}{ No. of studies } & \multicolumn{8}{|c|}{ Certainty assessment } & \multirow{2}{*}{ Sample } & \multirow{2}{*}{$1^{2}$} & \multirow{2}{*}{ Effect value $(95 \% \mathrm{Cl})$} & \multirow{2}{*}{ Overall certainty of evidence } \\
\hline & Risk of bias & Inconsistency & Indirectness & Imprecision & Publication bias & Large magnitude of effect & Dose response gradient & Plausible confounding & & & & \\
\hline \multicolumn{13}{|c|}{ Six-minute walking distance $(\mathrm{m})$} \\
\hline NRSI (4) & Serious $^{a}$ & Not serious & Not serious & Serious $^{\circ}$ & None & Yes $^{\mathrm{d}}$ & None & None & 262 & $39 \%$ & $W M D=57.68(41.55$ to 73.81$)$ & $\oplus \oplus \bigcirc \bigcirc$ (low) \\
\hline \multicolumn{13}{|c|}{ Dyspnoea score (points) } \\
\hline NRSI (2) & Serious $^{a}$ & Not serious & Not serious & Serious $^{c}$ & None & None & None & None & 105 & $0 \%$ & WMD $=-0.99(-1.45$ to -0.53$)$ & $\oplus \bigcirc \bigcirc \bigcirc$ (very low) \\
\hline \multicolumn{13}{|c|}{ Level of brain natriuretic peptide (pg /mL) } \\
\hline RCT (1), NRSI (1) & Serious $^{a}$ & Not serious & Not serious & Serious $^{\circ}$ & None & None & None & None & 102 & $14 \%$ & WMD $=-86.16(-103.39$ to -68.93$)$ & $\oplus \bigcirc \bigcirc \bigcirc$ (very low) \\
\hline \multicolumn{13}{|c|}{$\begin{array}{l}\text { Reduction in the mean pulmonary artery pressure } \\
(\mathrm{mmHg})\end{array}$} \\
\hline $\mathrm{RCT}(2)$ & Serious $^{a}$ & Serious $^{b}$ & Not serious & Serious $^{\circ}$ & None & None & None & None & 172 & $89 \%$ & $W M D=-4.13(-6.52$ to -1.74$)$ & $\oplus \bigcirc \bigcirc \bigcirc$ (very low) \\
\hline \multicolumn{13}{|c|}{ Mean pulmonary artery pressure $(\mathrm{mmHg})$} \\
\hline NRSI (2) & Not serious & Not serious & Not serious & Serious $^{c}$ & None & None & None & None & 144 & $0 \%$ & WMD $=-4.90(-10.36$ to 0.55$)$ & $\oplus \oplus \bigcirc \bigcirc$ (low) \\
\hline \multicolumn{13}{|c|}{ Systemic arterial oxygen saturation (\%) } \\
\hline NRSI (2) & Not serious & Not serious & Not serious & Serious $^{\circ}$ & None & None & None & None & 144 & $0 \%$ & $W M D=2.48(1.26$ to 3.71$)$ & $\oplus \oplus \bigcirc \bigcirc$ (low) \\
\hline \multicolumn{13}{|c|}{ Reduction in pulmonary vascular resistance (dyn $\cdot \mathrm{s} \cdot \mathrm{cm}^{-5}$ ) } \\
\hline $\mathrm{RCT}(1)$ & Not serious & Not serious & Not serious & Serious $^{\circ}$ & None & Yes $^{d}$ & None & None & 130 & NA & $W M D=-171.00(-311.49$ to -30.51$)$ & $\oplus \oplus \oplus \bigcirc$ (moderate) \\
\hline \multicolumn{13}{|c|}{ Pulmonary vascular resistance (Wood Units) } \\
\hline NRSI (1) & Not serious & Not serious & Not serious & Serious $^{\circ}$ & None & None & None & None & 60 & NA & WMD $=-1.02(-3.73$ to 1.69$)$ & $\oplus \oplus \bigcirc \bigcirc$ (low) \\
\hline $\mathrm{RCT}(1)$ & Not serious & Not serious & Not serious & Serious $^{\circ}$ & None & None & None & None & 130 & NA & WMD $=-1.10(-2.73$ to 0.53$)$ & $\oplus \oplus \oplus \bigcirc$ (moderate) \\
\hline \multicolumn{13}{|c|}{ Right atrium pressure $(\mathrm{mmHg})$} \\
\hline NRSI (3) & Serious $^{a}$ & Not serious & Not serious & Serious $^{c}$ & None & None & None & None & 164 & $15 \%$ & WMD $=-1.17(-2.14$ to -0.20$)$ & $\oplus \bigcirc \bigcirc \bigcirc$ (very low) \\
\hline \multicolumn{13}{|c|}{ Reduction in the cardiac index $\left(\mathrm{min} \cdot \mathrm{m}^{2}\right)$} \\
\hline $\mathrm{RCT}(1)$ & Not serious & Not serious & Not serious & Serious $^{\circ}$ & None & None & None & None & 130 & NA & WMD $=0.23(-0.18$ to 0.64$)$ & $\oplus \oplus \oplus \bigcirc$ (moderate) \\
\hline \multicolumn{13}{|c|}{ Cardiac index $\left(\min \cdot \mathrm{m}^{2}\right)$} \\
\hline NRSI (2) & Serious $^{a}$ & Not serious & Not serious & Serious $^{\circ}$ & None & None & None & None & 80 & $0 \%$ & WMD $=0.35$ (0.07 to 0.63$)$ & $\oplus \bigcirc \bigcirc \bigcirc$ (very low) \\
\hline \multicolumn{13}{|c|}{ Adverse event-headache (\%) } \\
\hline RCT (1), NRSI (3) & Serious $^{a}$ & Serious $^{b}$ & Not serious & Serious $^{\circ}$ & None & Yes $^{\circ}$ & None & None & 304 & $92 \%$ & $\mathrm{OR}=33.21(0.83$ to $1,334.18)$ & $\oplus \oplus \bigcirc \bigcirc$ (low) \\
\hline \multicolumn{13}{|c|}{ Adverse event-flushing (\%) } \\
\hline RCT (1), NRSI (2) & Serious ${ }^{a}$ & Serious $^{b}$ & Not serious & Serious $^{\circ}$ & None & Yes $^{\circ}$ & None & None & 244 & $77 \%$ & $\mathrm{OR}=17.02$ (0.98 to 294.15$)$ & $\oplus \oplus \bigcirc \bigcirc$ (low) \\
\hline \multicolumn{13}{|c|}{ Adverse event-dyspepsia (\%) } \\
\hline RCT (1), NRSI (2) & Not serious & Not serious & Not serious & Serious $^{\circ}$ & None & Yes $^{d}$ & None & None & 283 & $0 \%$ & $\mathrm{OR}=2.76$ (1.01 to 7.56$)$ & $\oplus \oplus \oplus \bigcirc$ (moderate) \\
\hline \multicolumn{13}{|c|}{ Adverse event-diarrhoea (\%) } \\
\hline RCT (1), NRSI (1) & Not serious & Not serious & Not serious & Serious $^{\circ}$ & None & None & None & None & 223 & $0 \%$ & $\mathrm{OR}=1.89$ (0.57 to 6.30$)$ & $\oplus \oplus \bigcirc \bigcirc$ (low) \\
\hline Adverse event-limb p & & & & & & & & & & & & \\
\hline RCT (1), NRSI (1) & Not serious & Not serious & Not serious & Serious $^{\circ}$ & None & None & None & None & 223 & $0 \%$ & $\mathrm{OR}=1.62$ (0.47 to 5.61$)$ & $\oplus \oplus \bigcirc \bigcirc$ (low) \\
\hline RCT (1), NRSI (2) & Not serious & Not serious & Not serious & Serious $^{\circ}$ & None & None & None & None & 283 & $0 \%$ & $\mathrm{OR}=1.01(0.06$ to 16.55$)$ & $\oplus \oplus \bigcirc \bigcirc$ (low) \\
\hline Incidence of clinical & & & & & & & & & & & & \\
\hline RCT (1), NRSI (2) & Not serious & Serious ${ }^{b}$ & Not serious & Serious $^{\circ}$ & None & Yes $^{d}$ & None & None & 283 & $77 \%$ & $\mathrm{OR}=3.36(0.19$ to 60.54$)$ & $\oplus \oplus \bigcirc \bigcirc$ (low) \\
\hline
\end{tabular}

